isotherm behaviour and the adsorption isotherm behaviour characterizing the linear elution of hydroearbons from gas-solid columns at temperatures below the boiling point of the hydrocarbons.

Isotherms convex to the pressure axis are well established for adsorption systems as type III of the Brunauer, Emmett and Teller classification, and are generally attributed to heats of adsorption being numerically less than the latent heat of vaporization of the adsorbate. Recent work (in preparation for publication) on the modification of active alumina with sodium hydroxide has shown that symmetrical elution of hydrocarbons at column temperatures below their boiling point is characterized by adsorbent-adsorbate interactions with heats of adsorption of approximately the same numerical magnitude as their heats of vaporization. In the case of cyclohexane, the adsorption heats are slightly lower and injection of extremely large samples results in elution peaks having sloping fronts and sharp rears. It has been deduced that such behaviour occurs when the original alumina surface has been covered with the modifier.

There appears to be little doubt that the modification of alumina to produce linear isotherms and symmetrical elution peaks (under the conditions of temperature stated) over the partial pressures normally used in gas chromatography results in changing the isotherm type from II or IV towards type III; it is of interest to note that a similar isotherm change was reported by Gregg and Stock ${ }^{2}$ for the system cyclohexane-calcium carbonate when the calcium carbonate was allowed to sorb sufficient water to form a complete monolayer on its surface.

Lobitos Oilfields, Ltd., C. G. Scot'T

The Refinery.

Ellesmere Port,

Wirral, Cheshire.

${ }^{1}$ Freeguard, G. F., and Stock, R., Nature, 192, 257 (1961).

2 Gregg, S. J., and Stock, R., Gas Chromatography 1960, 90 edit. by
Desty, D. H. (Butterworths, London, 1960).

\section{Second Virial Coefficient of Krypton at Low Temperatures}

THE second virial coefficient of kryptorn was determined for temperatures ranging from $109 \cdot 95^{\circ} \mathrm{K}$. to $270 \cdot 3^{\circ} \mathrm{K}$. The experimental technique has been described $^{1,2}$; one measures the difference between the volume expansions at the same pressure and temperature of krypton and hydrogen chosen as a standard of reference. The advantage of this method is that one can neglect the virial coefficients of higher order than the second. Commercial 'pure grade' krypton gas, supplied by Air Liquide S.A. Paris, was purified by distillation at low temperatures.

The triple point temperature and pressure of our sample were: $116.0 \pm 0.4^{\circ} \mathrm{K}$. and $547.48 \pm 0.04$ $\mathrm{mm}$. of mercury. These values are in good agree-

\begin{tabular}{|c|c|c|c|}
\hline & Table 1 & & \\
\hline $\begin{array}{c}\text { Temperature } \\
\left({ }^{\circ} \mathbf{K} .\right)\end{array}$ & $\begin{array}{l}\text { Measured differences } \\
\text { between the second } \\
\text { virial eoeffieient of } \\
\text { krypton and hydrogen } \\
\text { Bkrypton - Bnydrogeu } \\
\text { (c.c./mole) }\end{array}$ & $\begin{array}{l}\text { Deduced values } \\
\text { for the second } \\
\text { coefficient of } \\
\text { krypton } \\
\text { (c.c./mole) }\end{array}$ & $\begin{array}{c}\text { Quantum } \\
\text { correction } \\
\text { (c.c./mole) }\end{array}$ \\
\hline $\begin{array}{l}109 \cdot 95 \\
134 \cdot 1\end{array}$ & $\begin{array}{l}-360 \cdot 6 \\
-260 \cdot 2 \\
-261.1\end{array}$ & $\begin{array}{l}-358.4 \\
-255.2 \\
-256.1\end{array}$ & $\begin{array}{l}+0.96 \\
+0.51\end{array}$ \\
\hline $174 \cdot 4$ & $\begin{array}{l}-161 \cdot 4 \\
-161 \cdot 0\end{array}$ & $\begin{array}{l}-151.3 \\
-151.7\end{array}$ & +0.25 \\
\hline $235 \cdot 1$ & $\begin{array}{r}-101.0 \\
-100.7\end{array}$ & $\begin{array}{l}-88.5 \\
-88.2\end{array}$ & +0.11 \\
\hline $270 \cdot 3$ & $\begin{array}{r}-80.8 \\
-78.9\end{array}$ & $\begin{array}{l}-67.2 \\
-65.3\end{array}$ & +0.09 \\
\hline
\end{tabular}

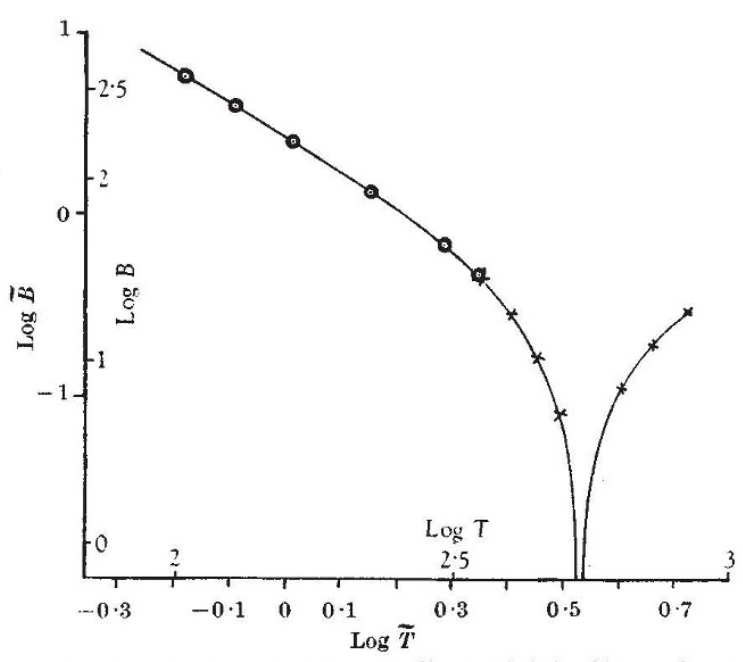

Fig. 1. $\times$, Results from Whalley and Schneider (ref. 6);

ment with those obtained in ref. 3 , namely, $115.97^{\circ} \mathrm{K}$. and $547.5 \mathrm{~mm}$. mercury. Hydrogen was 'research grade' gas of 99.99 per cent purity. This method gives only the difference between the virial coefficient of the two gases.

The second virial coefficient of hydrogen has been evaluated from Keyes's relation 4 . The intermolecular potential parameter $\varepsilon^{\times} / k$ and $\sigma$ (ref. 5) for krypton were determined by means of our experimental data, also taking into account the results in ref. 6 at higher temperatures; the method used was that described in ref. 9. The values which give the best fit with the experimental data are:

$$
\varepsilon^{\times} / k=168 \cdot 6^{\circ} \mathrm{K} \text {. and } \sigma=3.67 \AA .
$$

They should be compared with those deduced from second virial measurements at higher temperatures by other authors:

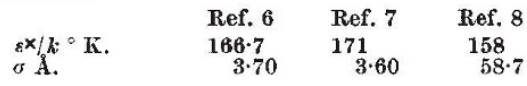

Values of the second virial coefficient of krypton are listed in Table 1. In Fig. 1 the reduced values of our experiments are plotted with some results from ref. 6 given as comparison. The full line is the Lennard Jones 6-12 theoretical curve. The agreement between our results, those in ref. 6 and the theoretical curve is excellent. From Fig. 1 it is clear that the 6-12 potential is a quite adequate representation of the krypton-krypton interaction in the gaseous atate.

This work was supported by the Institut Inter. universitaire des Sciences Nucleaires, Brussels.

$$
\text { G. Thomaes }
$$

Faculty of Sciences,

R. VAN STEENWINKKI.

Free University, Brussels.

'Thomaes, G., and van Steenwinkel, R., Rev. Sci. Inst., 31, 825 (1960).

2 Thomaes, G., and van Steenwinkel, R., Nature, 187, 229 (1960).

${ }^{3}$ Meilhuizen, J. J., and Commelin, C. A., Physica, 4, 1 (1947). Temperature-Its Measurement and Control in Science and Industry,
45 (Reinhold, New York, 1939).

${ }^{5}$ For definition, see Firchfelder, J. O., Curtisg, C. F., and Bird, R. B., Molecular Theory of Gases and Liquids (J. Wiley and Sons, Inc., New York, 1954).

6 Whalley, E., and Schneider, W. G., J. Chem. Phys., 28, 1644 (1955).

'Beattie, J. A., Barriault, R. J., and Brierly, J. S., J. Chem. Phys., 20, 1613 (1952).

${ }^{8}$ Newitt, D. M., Design of High Pressure Plant and the Properties of Fluids at High Pressure (Oxford Univ. Press, 1940).

'Lennard Jones, J. E., Proc. Roy. Soc., A, 106, 463 (1924). 